\title{
Ossification in Adult Rat Mandibular Condyle-SEM of Chondroclasia
}

\author{
Keith S. Lester ANd Major M. Ash, JR. \\ Department of Occlusion, University of Michigan Dental School, Ann Arbor, Michigan 48109
}

Received May 7, 1980, and in revised form October 31, 1980

\begin{abstract}
The morphology of the mineralized component at the osteochondral junction was studied in the mandibular condyle of 264-day-old rats. Specimens were rendered anorganic in $\mathrm{NaOCl}$, cut open with a scalpel, and the resulting surfaces examined in a scanning electron microscope. The extent of the mineralized cartilage plate and its relationship to invading vascular channels were visualized. Areas of resorption of calcified cartilage were identified and compared to areas of bone resorption. A likely sequence of events was reconstructed from the exposed internal surfaces: from initial chondroclasia in individual lacunae to extensive resorption of the cartilage plate; and from initial deposition of bone over the resorbed calcified cartilage cores to the organization of osteocyte lacunae and bony trabeculae. The mandibular condyle has not been examined in this way previously. Possible cellular mechanisms suggested by other studies to be operating at the osteogenic front are discussed in the light of the results.
\end{abstract}

The light microscope (LM) has been used extensively to study cellular organization and bone formation in the mandibular condyle and to compare the condyle with other sites (for example, 3, 14, 23, 35, 43, 62). The conclusion is commonly drawn that the histology of the condylar cartilage and the process of bone formation occurring beneath it have certain unique features about them. Not all LM investigations support this contention (5) and transmission electron microscope (TEM) studies tend to deny it $(40,46)$.

Serial sectioning of mineralized tissue for the TEM is technically difficult. Sampling and localizing the specimen and subsequently reconstructing it in three dimensions are also problems inherent to the technique. As a result, there are a number of TEM studies on the soft tissue of the mandibular condyle and the immediately adjacent mineralizing cartilage front $(1,2$, $47,67-69,71,72$ ). However, TEM data on the more deeply located resorbing cartilage front and mineralizing bone front are minimal (40).

Scanning electron microscope (SEM) study of anorganic specimens was antici- pated as a means of overcoming some of these technical difficulties. This approach has been used previously for cartilagebone junctions in long bone $(7,10,51,52)$. Our aim was to examine directly the surface morphology of the mineralized components of the ossification site in the mandibular condyle.

\section{MATERIALS AND METHODS}

The mandibular condyles of six young adult (264day-old) rats (Rattus norvegicus) were dissected postmortem after their being subjected to ether inhalation. Condylar heads were placed in a cold solution of $5.25 \%$ sodium hypochlorite (Chlorox) changed daily for a period of 4 days. The specimens were gently washed in distilled water to remove $\mathrm{NaCl}$; dehydrated through graded ethanols to absolute; air-dried and given a conducting coat of gold in an argon ion atmosphere (Polaron sputter-coater).

The endochondral junction was exposed by pressing a sharp, clean scalpel blade against the condylar surface. It was possible to prepare different angulations of internal surface and to return specimens for further sectioning after initial examination. Severed surfaces were prepared either predominantly perpendicular (coronal) to the cartilage plate (Fig. 1) or predominantly tangential to it (Fig. 4).

The coated specimens were examined in a SEM (JEOL JSM-U3) at $15 \mathrm{kV}$ and stereo-pair photomicrographs taken at a tilt angle of $5^{\circ}$ where appropriate. 

long canaliculi extending from it. The opposite side (Fig. 19) of this space (Fig. 15) shows a more advanced stage wherein bone deposition has covered the wall and the cartilage core (Fig. 20). The distribution of cartilage cores may be judged by the smeared areas within the sectioned bony trabeculae (Fig. 19).
Bone deposition upon a calcified cartilage core is illustrated in Figs. 22 and 23. Evidence exists here of osteoblastic activity and osteocyte lacuna formation within the previously resorbed chondrocyte lacuna bays. Two of the cartilage bays still retain calcospherites, evidence of their having been chondrocyte lacunae. The central

Figs. 1-23. All illustrations are scanning electron micrographs of severed surfaces of anorganic mandibular condyles from 264-day-old rats. Figs. 1-3 and 6-19 are of surfaces predominantly perpendicular to the articular surface and Figs, 4 and 5 and 12-23 are of surfaces predominantly tangential to it. Abbreviations are: b, cut or fractured bone; c, calcified cartilage; cf, calcifying cartilage front; $\mathrm{ch}$, chondrocyte lacuna; forming bone; os, osteocyte lacuna; $r$, resting bone; $r c$, resorbing cartilage; $v$, vascular channel; ${ }^{*}$, smeared (cut) cartilage surface.

FIG. 1. Low magnification of condyle severed in coronal plane showing: calcified cartilage plate; vascular channels and marrow spaces oriented radially in region of osteochondral junction; and fractured bone of the ramus with predominantly longitudinally oriented vascular channels. Arrows are localization for Fig. 2. Field width $=2.37 \mathrm{~mm}$.

FIG. 2. Enlargement of area between open arrows in Fig. 1. From top to bottom are seen: the mineralizing cartilage front; the smeared, cut surface of the cartilage plate; forming, resting, and fractured bone surfaces of trabeculae; and vascular channels. Arrows are localization for Fig. 3. Field width $=237.5 \mu \mathrm{m}$.

Fig. 3. Detail of area between arrows in Fig. 2 showing: exposed fibrils in a resorbing area on the inferior aspect of the cartilage plate adjacent to forming bone and an osteocyte lacuna. Field width $=52.2 \mu \mathrm{m}$.

Fic 4 Sunerior view of sondyle showing tanoential sectings of surfare made to exnose the ostengenic site

and internal bone surfaces. Note the calcified cartilage; vascular channels; cut cartilage plate and the cut bone surface. The open arrow is localization for Fig. 5. Field width $=1.19 \mathrm{~mm}$.

FIG. 5. Stereopair enlargement of area in Fig. 4-arrow to same point although image rotated somewhat. Note the variable thickness of the mineralized cartilage plate and the proximity and extent of invasion of the vascular channels. Resorbing cartilage areas balloon irregularly from the walls of the channels (at solid arrows). Field width $=475 \mu \mathrm{m}$.

FIG. 6. Longitudinally cut surface rotated to profile the mineralizing front of the cartilage plate. Open arrows are localization for Fig. 7. Field width $=550 \mu \mathrm{m}$.

Frg. 7. Enlargement of arrowed area in Fig. 6. Part of a naturally occurring internal surface layer showing an area of resorption involving multiple chondrocyte lacunae. The large calcospherites (open arrows) forming the inner walls of the lacunae are in varying stages of dissolution. Forming bone is seen to the left of the rim of the resorptive crater (at solid arrows). Field width $=67.8 \mu \mathrm{m}$.

FIG. 8. Naturally occurring inner surface of the mineralized cartilage plate showing a single chondrocyte lacuna in an advanced stage of resorption. The arrows are for localization for Fig. 9. Field width $=48.5 \mu \mathrm{m}$.

FIG. 9. Enlargement of the arrowed resorbing cartilage area in Fig. 8 showing interweaving fibrils characteristic of cartilage. The lining calcospherites have completely disappeared. Field width $=14.6 \mu \mathrm{m}$.

FIG. 10. Survey view of the surface of subperiosteal bone of the ramus immediately beneath the condylar cartilage showing a multitude of Howship's lacunae. Arrow localizes Fig. 9. Field width $=686 \mu \mathrm{m}$.

FIG. 11. Detail from area in Fig. 10; the arrow is to same point in both. Note the exposed, interwoven collagen fibril bundles and osteocyte lacunae typical of a resorbing bone surface. Compare with cartilage in Fig. 9. Field width $=67.8 \mu \mathrm{m}$.

FIG. 12. Low-magnification stereopair of tangential section of condyle showing the three-dimensional complexity of the trabeculae beneath the cartilage plate. Arrows are for localization of Figs. 13 and 14. Field width $=514 \mu \mathrm{m}$.

FIG. 13. Stereopair of detail from trabeculum in Fig. 12. The closed arrow indicates the same point in both figures although the field is rotated. The complete bone surface has undergone resorptive remodeling. Portions of five osteocyte lacunae are exposed. Collagen fibrils typical of a central resorbed cartilage core may be seen at arrow. Field width $=38 \mu \mathrm{m}$.

FIG. 14. Stereopair of detail from Fig. 12. The open arrow points to the same area in both figures. The concavities above and to the left and the loss of the large calcospherites of the lacunar bed are evidence of cartilage resorption. Field width $=39.6 \mu \mathrm{m}$. 

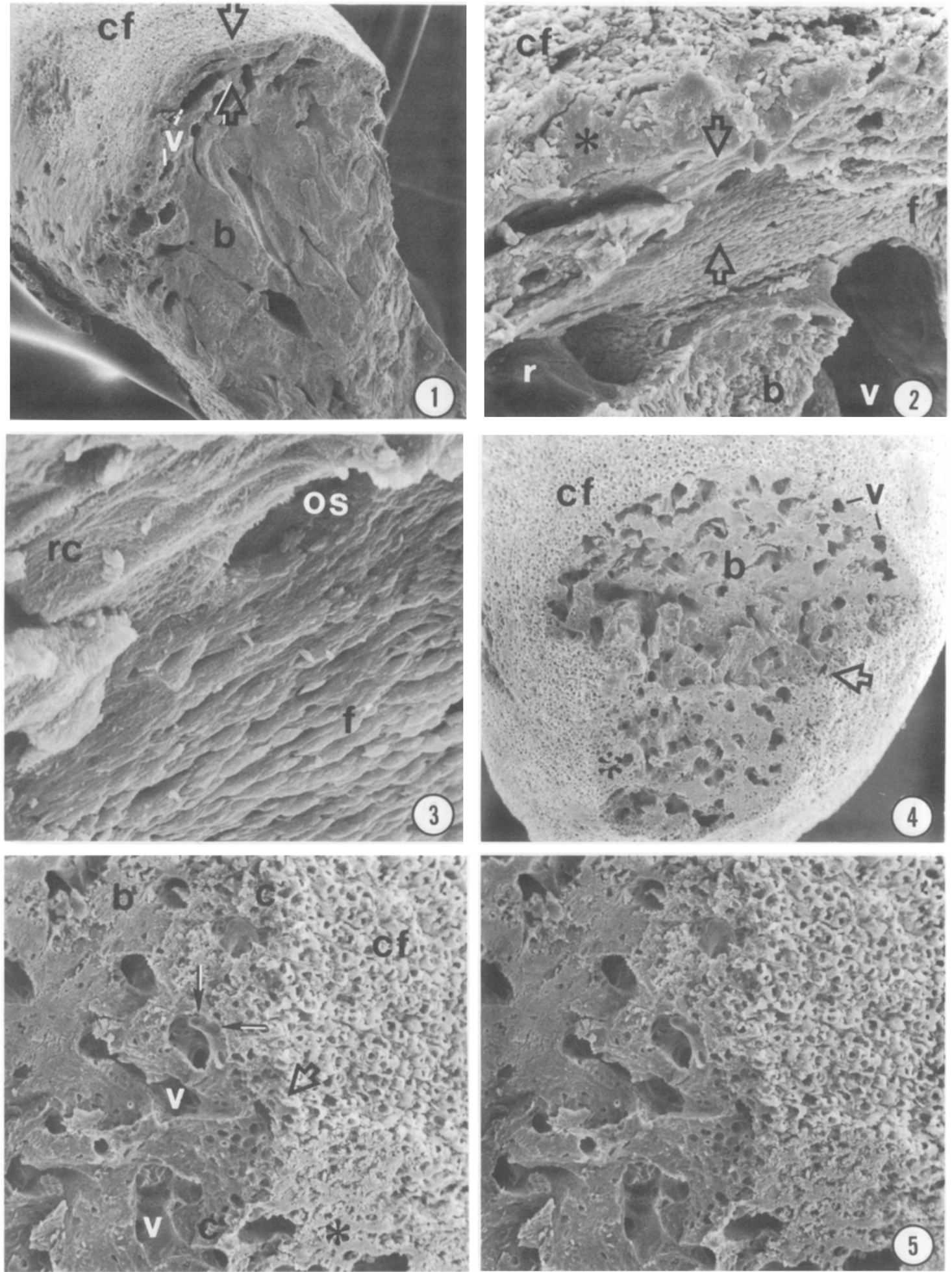

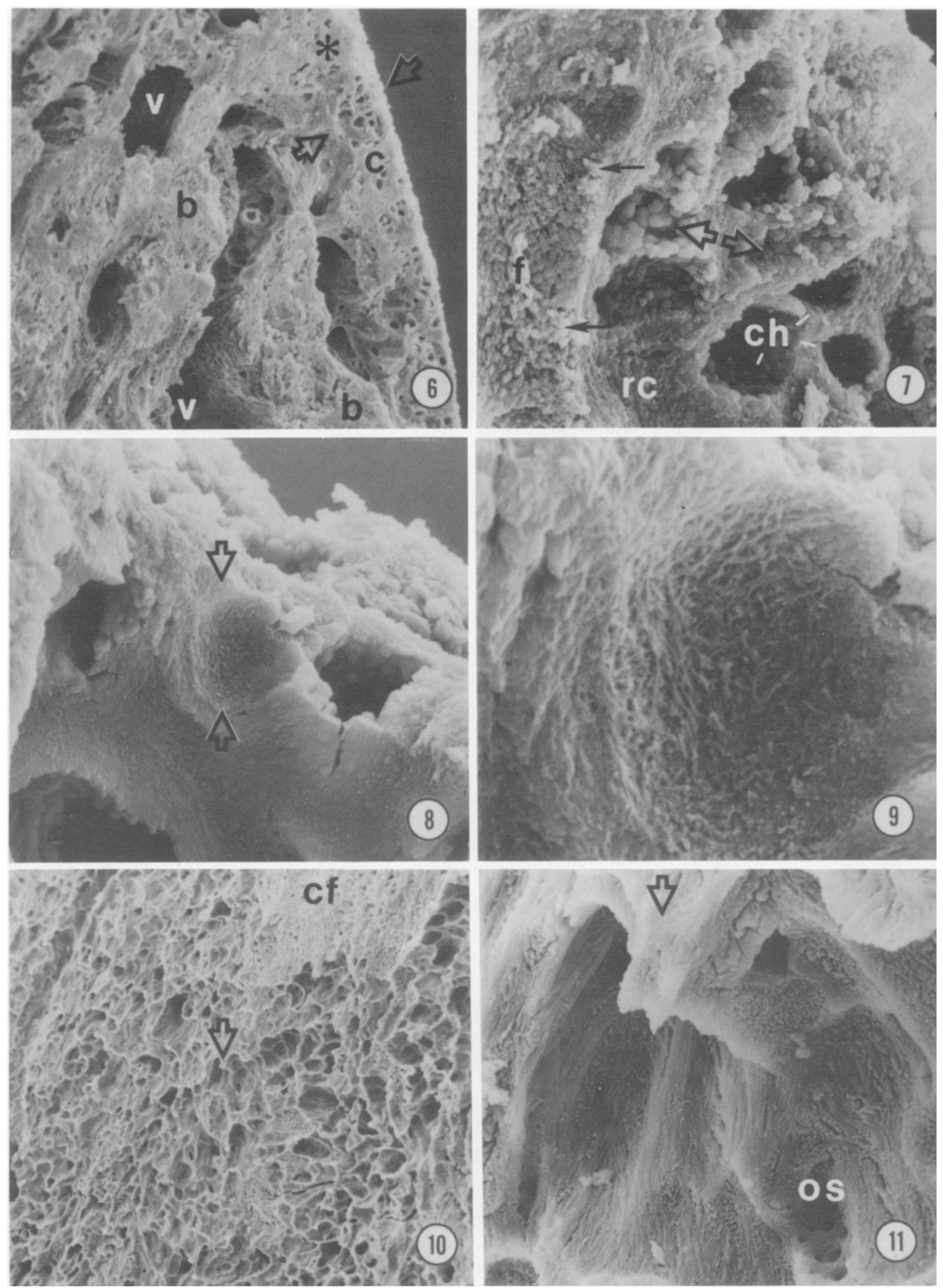

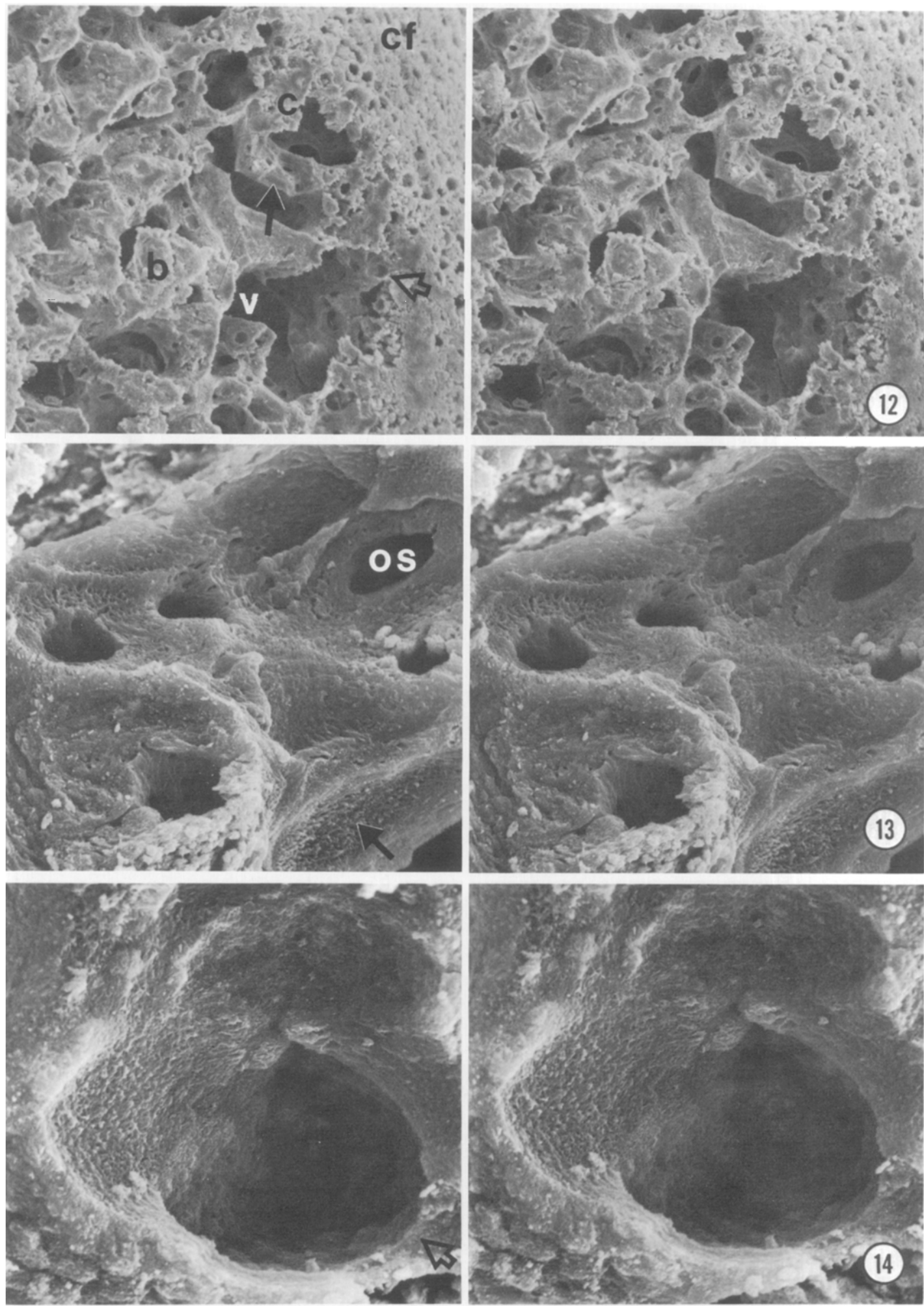
bay (enlarged in Fig. 23) is organized as an osteocyte lacuna and lies at the junction between forming bone and resorbing calcified cartilage.

\section{DISCUSSION}

Fractured preparations of anorganic rat mandibular condyle examined in the SEM provide useful information on the process of ossification occurring there. Areas of resorption of calcified cartilage can be positively identified and compared to areas of bone resorption, both periosteal and endosteal. A sequence of events can be reconstructed from the exposed internal surfaces: from initial resorption in the chondrocyte lacunae to the extensive resorption of areas containing multiple lacunae; and from initial mineralization of the fibrillar component of bone over the calcified cartilage core to the organization of osteocyte lacunae and bony trabeculae. The degree of activity at this stage (264 days) suggests that examination of much younger animals (17-20 days) would be especially rewarding.

\section{Is Ossification in the Mandibular Condyle Unique?}

The view has been put repeatedly that the cartilage of the condyle and the ossification occurring there are quite different from that in the growth plate of the primary cartilaginous skeleton $(19-21,23,35)$. The differences described, mostly in rat condyle, include:

(i) the lack of a zone of oriented chondrocytes;

(ii) appositional rather than interstitial growth;

(iii) the onset of cartilage resorption prior to capillary invasion of the osteogenic site;

(iv) a significantly different blood supply pattern;

(v) a lack of calcified cartilage cores as scaffolding for initial bone deposition, that is to say, a "practically nonexistent" classical primary spongiosa (23).

The ossification process in the condyle was compared more favorably by these authors (22) with that occurring beneath the articular cartilage of long bones.

That a specific type of endochondral ossification exists in mouse mandibular condyle was suggested on the basis of the observed retention of vitality of some of the hypertrophic chondrocytes and their subsequent transformation directly into bone cells $(62-66)$. The idea was seen to hold some attraction in view of in vitro and in vivo experiments indicating the multipotentiality of the cells of the proliferative zone of the condyle $(47,48)$. The question of

FIG. 15. Tangential section of condyle showing a naturally occurring surface (between the open arrows) leading away from the mineralizing front of cartilage. Figs. 16-18 and 21 are enlargements of different areas of this field and Figs. 19 and 20 illustrate the left-hand wall of the same arrowed space. Field width $=486 \mu \mathrm{m}$.

FIG. 16. Detail from arrowed area in Fig. 15. A sequence of events can be reconstructed from chondrocyte lacuna bed (1); to resorptive channel in the cartilage plate (2); to commencement of bone formation (3); to organized osteocyte lacuna (4). Part of the field is enlarged in stereoscopic view in Fig. 21 . Field width $=100.7$ $\mu \mathrm{m}$.

FIG. 17. Detail from area between 2 and 3 in Fig. 16 showing junction of cartilage resorption and bone formation about an osteocyte lacuna. Field width $=20.4 \mu \mathrm{m}$.

FIG. 18. Detail from area (rc) in Fig. 16 showing profiled osteochondral junction (j) and a lacuna (l) with long, fine canaliculi (at arrows) extending through the resorbing calcified cartilage. Field width $=20.4 \mu \mathrm{m}$.

Frg. 19. Same field as in Fig. 15, viewed from the other side and enlarged to show the opposing, more deeply located and correspondingly more developed wall of the same marrow space. Note cartilage cores (c). Arrow for Fig. 20. Field width $=340 \mu \mathrm{m}$.

FIG. 20. Detail from Fig. 19, arrow to same osteocyte lacuna. Note also forming bone and calcified cartilage core. Field width $=44 \mu \mathrm{m}$. 

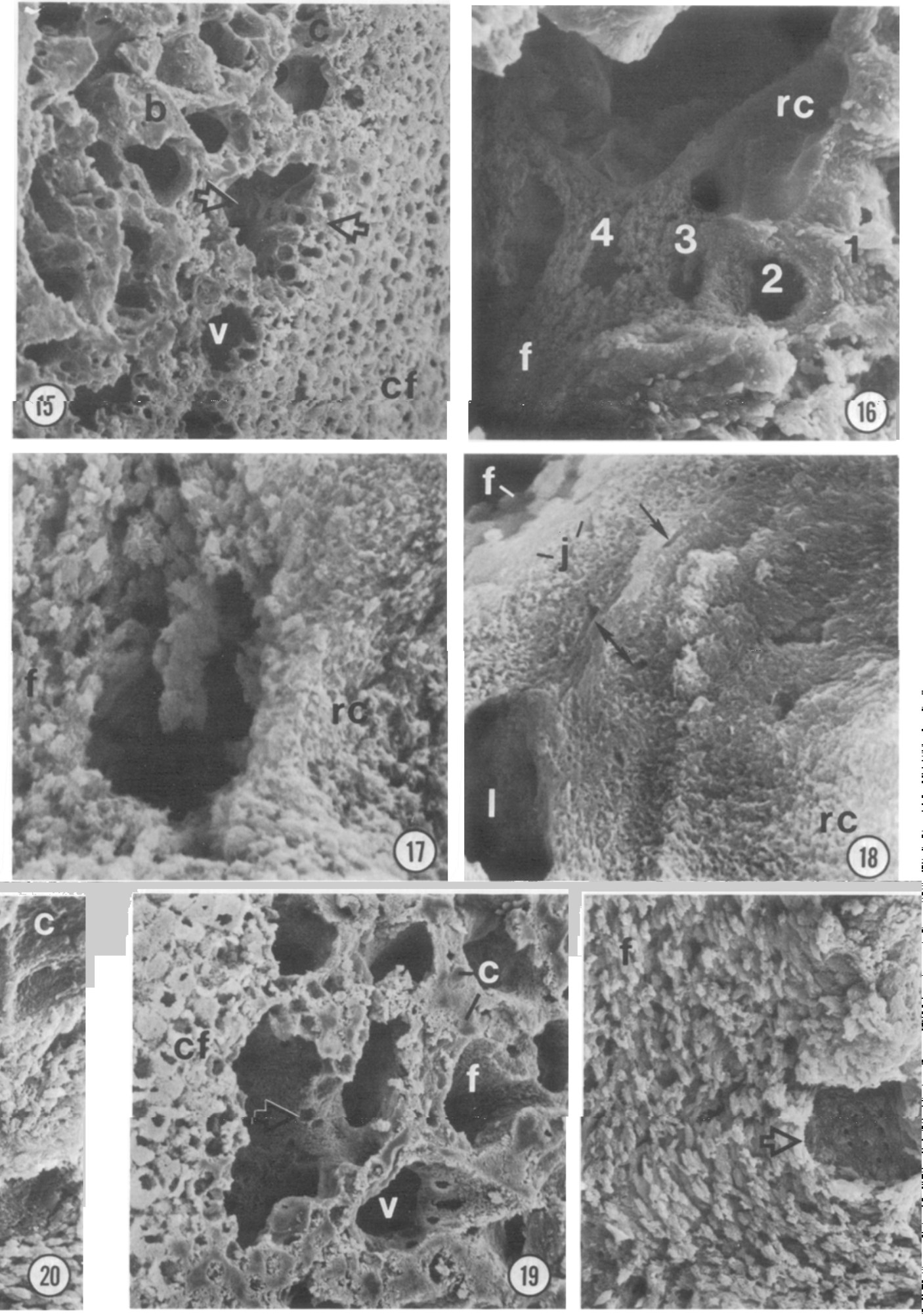

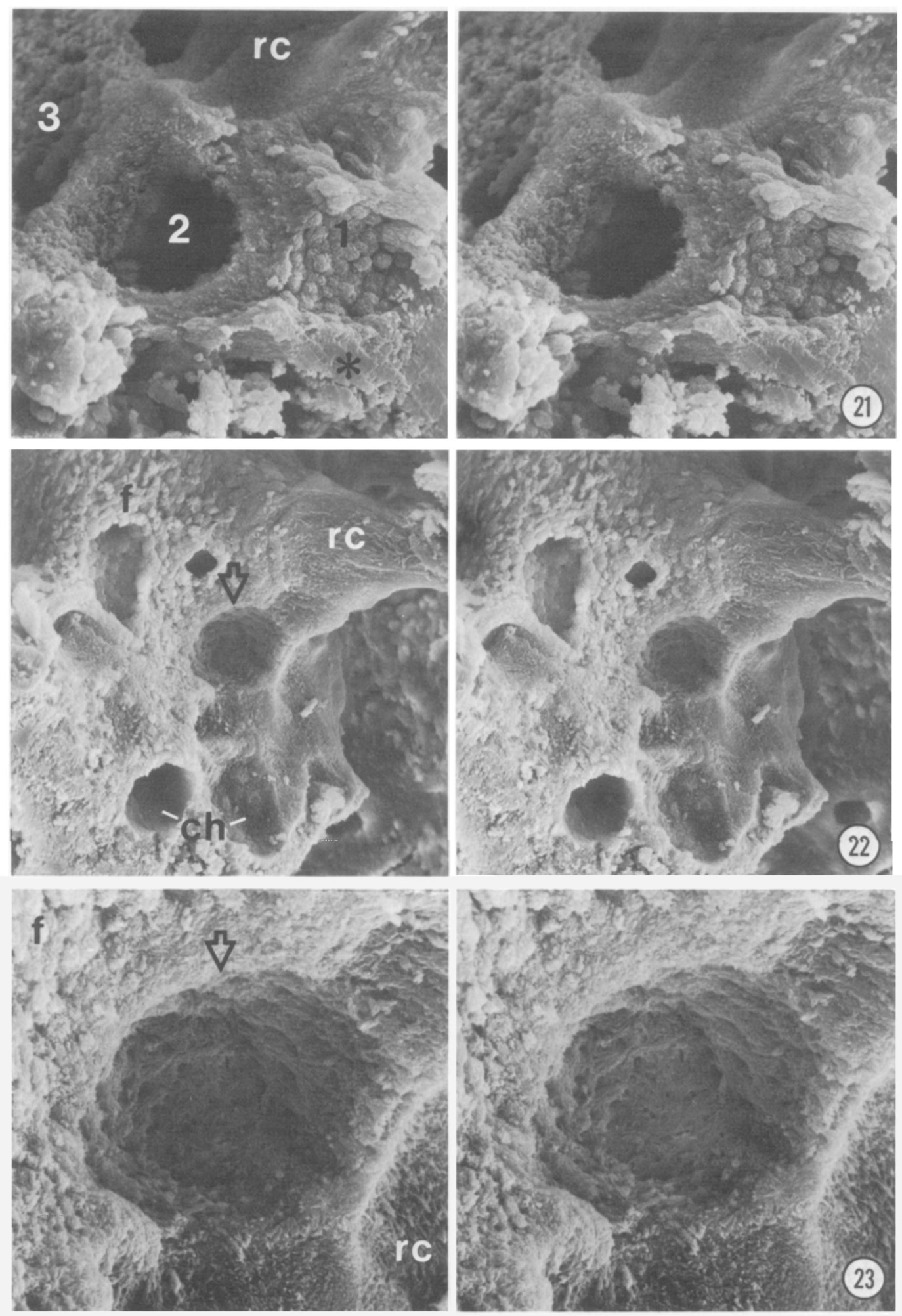
transformation of cartilage to bone is, of course, an old one $(12,17,74)$. Evidence that hypertrophic chondrocytes may survive mineralization and dissolution of their matrix and transform to other cell types had been presented earlier for rat rib (29), mouse pubes (15), and tibia of the domestic fowl (44). The possibility has been denied by others (4) and is reviewed elsewhere $(16,28)$.

A LM study comparing the condyle with the penile bone in the rat concluded that "undoubted uniqueness" could be attributed to neither (5). One TEM study has denied any inherent differences in the pattern of mineralization and erosion between the epiphyseal growth plate and the developing mandibular condyle finding them "fundamentally similar" (40). Another study has positively identified lysozomes in the hypertrophic chondrocytes and suggested cellular autolysis as their primary function (46). The position then, that the mandibular condyle is unique in its ossification process is becoming increasingly difficult to maintain.

\section{Primary Spongiosa}

Obviously, we disagree with the reported lack of calcified cartilage cores to the bony trabeculae formed immediately beneath the cartilage plate $(23,57)$, acknowledging at the same time that our material is from considerably older animals (Figs. 19-23). It is very likely that this and similar points raised in support of the uniqueness of the osteogenic process in the mandibular condyle are partly the understandable result of a combination of the limited resolution af- forded by the LM and the difficulty of three-dimensional reconstruction of sectioned material. We did, however, find only a small number of primary trabeculae oriented perpendicular to the outer condylar surface (Fig. 12). This is consistent with the known lack of oriented columns of hypertrophic chondrocytes $(23,76)$ and made the search for resorptive cartilage sites more difficult.

It is interesting to note that a similar lack of orderliness exists in the hypertrophic chondrocytes in developing chick vertebrae (16). A major difference in chick vertebrae however, is that in this "short bone" the larger part of the matrix does not calcify and trabeculae develop by deposition of bone osteoid on uncalcified matrix. Calcification of cartilage matrix in the mandibular condyle of the rat is very extensive (42).

\section{Capillaries and Ossification}

The role of capillaries has always been a major factor in consideration of the transition of cartilage to bone $(11,16,34,41,58$, $60,73)$. Stereopair examination shows vascular channels invading the mineralized cartilage plate and extensive resorptive activity within the walls of these (Fig. 5). The close proximity of these channels to any resorptive site observed at the osteogenic front is so consistent (Fig. 15) that we would not care to separate the two processes (see also (40)). However, the adult stage examined here may differ from very much earlier phases of rapid growth examined by others and only comparison of similarly aged specimens would clarify this.

FIG. 21. Stereopair enlargement of middle right section of Fig. 16 to show the morphology of a chondrocyte lacuna undergoing initial resorption (1); large vascular resorptive channel (2) in the cartilage plate and the commencement of bone formation (3). Resorbing cartilage surface at top. Field width $=56.2 \mu \mathrm{m}$.

FIG. 22. Stereopair of primary spongiosum showing mineralized cartilage core undergoing resorption and with bone forming over it. There is evidence of the resorbed chondrocyte lacunae acting as preferred sites for the location of osteocyte lacunae. Arrow is for localization of Fig. 23. Field width $=67.7 \mu \mathrm{m}$.

FIG. 23. Stereopair of detail from central lacuna in Fig. 22 (arrow to same point). Note forming bone, resorbing cartilage, mineralized collagen fibrils, forming bed of osteocyte lacuna, and canaliculi opening from it. Field width $=22 \mu \mathrm{m}$. 


\section{Chondroclasia}

Our material demonstrated both frank channels and lacunae with canaliculi relatable to invasive cellular extensions at the resorbing calcified cartilage front (Figs. 15$18,21)$. We should emphasize that our specimens consisted only of mineralized material: osteoid and uncalcified cartilage being removed with the cellular component during preparation. Mineralization of the original cartilage plate is, however, very extensive (42). Uncalcified cartilage, if present, would be small in amount at the resorptive front in vivo and confined mostly to a circumcellular site. The mechanisms involved then, in resorption in the adult mandibular condyle at the osteochondral junction are primarily aimed at the dissolution of mineralized cartilage.

It has been reported by LM (18) and TEM $(16,59)$ that uncalcified cartilage and calcified cartilage resorb differently, easily identifiable chondroclasts being associated only with the latter. However, the exact relationship between the chondroclasts and the vascular, perivascular, and endothelial elements in terms of origin and function remains unclear $(11,39,60,73)$.

The osteoclast/chondroclast is currently the subject of a great deal of research activity (for reviews, see $6,26,31,61$ ). The point is often made that cells involved in the breakdown of calcified cartilage are ultrastructurally indistinguishable from osteoclasts and that no distinction of nomenclature need be made in the type of "clast" referred to $(31)$. The characteristic spanning by chondroclasts of several opened cartilage lacunae with long amoeboid processes was noted in a TEM study of Meckel's cartilage (58). Cultured osteoclasts in rat parietal and frontal bone have been described with the SEM as being of two types; one a "buried fimbrillated variety" difficult to dissect from its Howship's lacuna in fixed specimens (37). These two observations are compatible with our Fig. 18 where part of a lacuna and its extending canaliculi run through a resorptive cartilage zone. We presume this to be the impression of the cell body of a chondroclastic cell and its extending, invasive processes within the resorbing cartilage. Numerous cell processes have been described for the hypertrophic chondrocyte in other sites $(30,56)$ and tubules have been illustrated within articular cartilage (49). However, the pattern illustrated here is quite unlike the intact chondrocyte beds previously described in rat mandibular condyle (42).

The presence of insinuating osteoclast processes (see also (70)) offers a possible explanation for the relatively haphazard distribution of resorptive areas in the exposed cartilage plate and the difficulty experienced in relating these definitely to the presence of capillaries. On the other hand, the haphazard nature of the resorptive activity could be taken as support for the idea of resorptive activity by single resident hypertrophic chondrocytes suggested elsewhere $(40,59)$. There are fields in our material where isolated chondrocyte lacunae show evidence of resorption (Figs. 8, 14).

\section{The Question of Cellular Transformation}

Conclusions concerning cellular activity are necessarily indirect for anorganic specimens as only the mineralized component remains. Nonetheless, the high sampling rate afforded by the SEM is a distinct advantage over sectioned material and the TEM (see also (37)). The multipotential nature of the proliferative zone in the condyle is well established $(45,48,54)$. With regard to the possibility of chondrocyte transformation to osteoclasts and osteoblasts, it is quite clear from our material that the relative proportions of these cell-types are quite different. Chondrocyte lacunae far outnumber osteocyte lacunae (Figs. 5, 7) while resorptive areas must be diligently searched out. Even allowing for direct transformation of some chondrocytes to osteoblasts, the population ratios indicate quite definitely that the majority of chondrocytes have no potential home site within the osteogenic front. 
Evidence is presented here of resorbed chondrocyte lacunae acting as preferred sites for the establishment of osteocyte lacunae (Figs. 16, 22). What the origin of the osteoblasts is we cannot say from our material. However, the topography could easily be interpreted by LM as offering support for the involvement of chondrocytes in osteogenesis. Until more of the history of the cells at the osteogenic front is elucidated by other than LM, we are reluctant to draw further conclusions from our material.

\section{Species Specificity}

It would be unwise for us to extrapolate too much from the rat to the human for a number of reasons. There are many wellknown dental features of the laboratory rat which make it atypical not only of mammals generally but of its own order. Species specificity of the temporomandibular joint is likewise well established $(50,55)$. Indeed, the rat has no temporomandibular joint as such but rather a mandibular-squamosal joint and lacks a postglenoid process $(14,25)$. The condyle is elongated anteroposteriorly and experimental retrusion rapidly produces a proliferative rather than a resorptive response in adult animals (25, $33)$. There is also evidence of changes resembling remodeling or arthrosis as a result of extraction or prosthetic interference (for a review, see (13)). The rat also possesses more secondary skull cartilages than other animals (75). Other differences have been noted in long bones of small laboratory rodents compared to larger mammals: the bone is laminar and lacks Haversian systems (24); most of the epiphyses remain open throughout life and the osteochondral junction is irregular in outline and has a relatively sparser fibril component $(32,53)$. Finally, a report on the vascularity of the femoral head in rabbits noted that the results "should not be freely related to the human condition" (27) because of significant differences.

We are reluctant to prolong existing discussion in the literature on the relative classification both of condylar cartilage and of its process of ossification. It is our opinion that more high-resolution data are needed on the accompanying cellular and extracellular changes at different ages and that these observations need be made with an awareness of potentially significant species differences.

This study was supported by USPHS Grant DE 02731-13 and the Biomedical Research Support Programme of the University of Michigan School of Dentistry. The animals were kindly made available by $\mathrm{Dr}$. J. Avery and Mr. H. Kazlaukas of the Dental Research Institute, University of Michigan. The microscopy was carried out in the EM laboratories of Dr. Bigelow, Engineering Department, University of Michigan. We are happy to thank Dr. A. Boyde, University College London, for his helpful discussion of the results.

\section{REFERENCES}

1. Appleton, J. (1975) Arch. Oral Biol. 20, 823-826.

2. Appleton, J. (1978) Arch. Oral Biol. 23, 719-723.

3. Baume, L. J. (1970) Amer. J. Orthod. 58, 537551.

4. Bentley, G., And Greer, R. B. (1970) J. Bone Joint Surg, 52B, 571-577.

5. Beresford, W. A. (1975) Amer. J. Orthod. 68, 189-195.

6. Bomb'i, J. A., Ribas-Mujal, D., and Truetta, J. (1978) Clin. Orthop. 130, 273-284.

7. Boyde, A. (1972) in Bourne, G. H. (Ed.), The Biochemistry and Physiology of Bone, 2nd ed., Vol. 1, pp. 259-310, Academic Press, New York.

8. Boyde, A. (1973) Brit. Dent. J. 134, 319-328,

9. Boyde, A., ANd Hobdell, M. H. (1969) Z. Zellforsch. 93, 213-231.

10. Boyde, A., AND Jones, S. J. (1972) in SLAVkin, H. C., AND Bavetta, L. A. (Eds.), Developmental Aspects of Oral Biology, pp. 263-267, Academic Press, New York.

11. Cameron, D. A. (1961) J. Bone Joint Surg. 43B, 590-594.

12. Carey, E. J., And Zeit, W. (1928) Anat. Rec. 36, 51-67.

13. Carlsson, G. E., and Oberg, T. (1974) in Melcher, A. H., AND ZARB, G. A. (Eds.), Oral Science Reviews, Vol. 6, pp. 53-86, Munksgaard, Copenhagen.

14. Collins, D. A., Becks, H., Simpson, M. E., AND Evans, H. M. (1946) Amer. J. Orthod. 32, 431442.

15. Crelin, E. S., ANd Koch, W. E. (1967) Anat. Rec. 158, 473-484.

16. Crissman, R. S., and Low, F. N. (1974) Amer. J. Anat. 140, 451-470.

17. Dawson, A. B. (1929) Anat. Rec. 43, 109-123.

18. Dodds, G. S. (1932) Amer. J. Anat. 50, 97-127. 
19. Durkin, J. F. (1972) Amer. J. Orthod. 62, 15-41.

20. Durkin, J. F., Irving, J. T., And Heeley, J. D. (1969) Arch. Oral Biol. 14, 1365-1371.

21. Durkin, J. F., Heeley, J. D., And Irving, J. T. (1971) Arch. Oral Biol. 16, 689-706.

22. Durkin, J. F., Irving, J. T., ANd Heeley, J. D. (1971) Arch. Oral Biol. 16, 827-829.

23. Durkin, J. F., Heeley, J. D., AND Irving, J. T. (1973) in Melcher, A. H., and Zarb, G. A. (Eds.), Oral Science Reviews, Vol. 6, pp. 2999, Munksgaard, Copenhagen.

24. Enlow, D. H., AND Brown, S. O. (1958) Tex. J. Sci. 10, 18-27.

25. Folke, L. E., ANd Stallard, R. E. (1966) $J$. Periodont. Res. 1, 79-89.

26. Göthlin, G., AND Ericsson, J. L. E. (1976) Clin. Orthop. 120, 201-231.

27. Greenwald, A. S., And Haynes, D. W. (1969) J. Bone Joint Surg. 51B, 747-753.

28. Hall, B. K. (1972) Anat. Rec. 173, 391-404.

29. Holtrop, M. E. (1965) in Fleisch, H., BlackWOOD, H. J., AND OwEN, M. (Eds.), Third European Symposium on Calcified Tissues, pp. 32-36, Springer-Verlag, Berlin.

30. Holtrop, M. E. (1972) Calc. Tissue Res. 9, 140151.

31. Holtrop, M. E., and King, G. J. (1977) Clin. Orthop. 123, 177-196.

32. Hough, A. J., Banfield, W. G., Mottram, F. C., AND SokolofF, L. (1974) Lab. Invest. 31, 685-695.

33. Ingervall, B., Freden, H., and Heyden, G. (1972) Arch. Oral Biol. 17, 661-671.

34. IrVing, M. H. (1964) J. Anat. 98, 631-639.

35. Irving, J. T., ANd Durkin, J. F. (1965) Arch. Oral Biol. 10, 179-185.

36. JoNEs, S. J., AND Boyde, A. (1970) in JohaRI, O. (Ed.), Scanning Electron Microscopy, pp. 193-200, ITT Research Institute, Chicago, Illinois.

37. Jones, S. J., AND Boyde, A. (1977) Cell Tissue Res. 185, 387-397.

38. Jones, S. J., Lozdan, J., ANd Boyde, A. (1972) Brit. Dent. J. 132, 57-64.

39. Kalayjian, D. B., AND CoOPeR, R. R. (1972) Clin. Orthop. Rel. Res. 85, 242-256.

40. Larsson, A. (1976) Anat. Rec. 185, 171-185.

41. Larsson, A., And Larsson, S. E. (1978) Acta Pathol. Microbiol. Scand. (A)86, 211-223.

42. Lester, K. S., AND Ash, M. M. JR. (1980) $J$. Ultrastruct. Res. 72, 141-150 (1980).

43. Levy, B. M. (1948) J. Amer. Dent. Assoc. 36, $177-182$.

44. Lufti, A. M. (1971) Acta Anat. 79, 27-35.

45. Metkle, M. C. (1973) Arch. Oral Biol. 18, 10111020.

46. Meikle, M. C. (1975) J. Anat. 119, 85-96.

47. Meikle, M. C. (1976) Arch. Oral Biol. 21, 33-43.

48. Melcher, A. H. (1971) Arch. Oral Biol. 16, 13791391.

49. Minns, R. J., And Stevens, F. S. (1977) J. Anat. 123, $437-457$.
50. Noble, H. W. (1973) in Melcher, A. H., AND ZARB, G. A. (Eds.), Oral Science Reviews, Vol. 6, pp. 3-28, Munksgaard, Copenhagen.

51. Ornoy, A., And Langer, Y. (1978) Isr. J. Med. Sci. 14, 745-752.

52. Ornoy, A., Sekeles, E., Smith, P., Simkin, A., AND Koch, G. (1976) Amer. J. Pathol. 82, 7184.

53. Palfrey, A. J. (1973) in Kennedi, R. M. (Ed.), Perspectives in Biomedical Engineering, pp. 139-145, MacMillan, London.

54. Petrovic, A. G., Stutzmann, J. J., And OudET, C. L. (1975) in McNamara, J. A. (Ed.), Determinants of Mandibular Form and Growth, pp. 101-153, Univ. of Michigan, Ann Arbor.

55. Poole, D. F. G. (1976) in Anderson, D. J., AND MatThews, B. (Eds.), Mastication, pp. 1-4, Wright, Bristol.

56. Reddi, A. H., ANd Anderson, W. A. (1976) J. Cell Biol. 69, 557-572.

57. Ronning, O., And Koski, K. (1967) Dent. Pract. 17, 448-450.

58. Savostin-Asling, I., ANd Asling, C. W. (1975) Anat. Rec. 183, 373-391.

59. Schenk, R. K., SPIRo, D., AND Wiener, J. (1967) J. Cell Biol. 34, 275-291.

60. Schenk, R. K., WienER, J., AND SPIRo, D. (1967) Acta Anat. 69, 1-17.

61. Scott, B. L., And Pease, D. C. (1956) Anat. Rec. 126, 465-495.

62. Silbermann, M., And Frommer, J. (1972) Anat. Rec. 172, 659-668.

63. Silbermann, M., And Frommer, J. (1972) Anat. Rec. 174, 503-512.

64. Silbermann, M., and Frommer, J. (1972) Amer. J. Anat. 135, 359-370.

65. Silbermann, M., and Frommer, J. (1973) Arch. Oral Biol. 18, 1549-1554.

66. Silbermann, M., AND Frommer, J. (1974) Acta Anat. 90, 330-346.

67. Silva, D. G. (1969) J. Ultrastruct. Res. 26, 148162.

68. Silva, D. G. (1971) Arch. Oral Biol. 16, 889-896.

69. Silva, D. G., ANd Hart, J. A. L. (1967) J. Ultrastruct. Res. 20, 227-243.

70. Soskolne, W. A. (1978) Cell Tissue Res. 195, 557-564.

71. Toller, P. A. (1977) Int. J. Oral Surg. 6, 297312.

72. Toller, P. A., And Wilcox, J. H. (1978) Oral Surg. 45, 232-245.

73. Trueta, J., And Little, K. (1960) J. Bone Joint Surg. 42B, 367-376.

74. VAN der STRICht, O. (1890) Arch. Biol. 10, 141.

75. VinkKa, H. (1979) Proc. Finn. Dent. Soc. 75, 4649.

76. Wright, D. M., And Moffet, B. C. (1974) Amer. J. Anat. 141, 235-250. 